\title{
В.В. ЮРЧЕНКО
}

\section{СПОСОБ ПРОФИЛАКТИКИ ПОСТПАПИЛЛОТОМИЧЕСКИХ КРОВОТЕЧЕНИЙ}

\author{
ФГБОУ ВПО «Хакасский государственный университет им. Н. Ф. Катанова», г. Абакан, \\ Российская Федерация
}

Цель. Снизить частоту постпапиллотомических кровотечений у пациентов с нарушениями в системе гемостаза, возникающими при механической желтухе.

Материал и методы. Поставленная цель достигалась путем двухэтапного проведения эндоскопической папиллосфинктеротомии (ЭПСТ) с межэтапных стентированием желчных протоков. Первый этап включал в себя незначительное (до разобщения устьев общего желчного и главного панкреатического протоков) рассечение большого дуоденального сосочка и эндобилиарное стентирование. При нормализации биохимических и коагуляционных показателей проводилось удаление эндопротеза и максимальная ЭПСТ канюляционным способом. Эффективность метода была оценена при сравнении результатов в двух группах пациентов с механической желтухой. В группе исследования (93 пациента) ЭПСТ выполняли в два этапа. В группе сравнения (91 пациент) использовалась общепринятая одномоментная ЭПСТ.

Результаты. Смещение эндопротеза в группе сравнения в первые сутки выявлено в пяти наблюдениях $(5,4 \%)$, при этом в трех случаях $(3,2 \%)$, желчь поступала в двенадцатиперстную кишку свободно. У этих трех пациентов замену стента не проводили, т.к. они функционировали. В двух случаях произведена замена эндопротезов. Кровотечения после ЭПСТ в группе исследования развились у $5(5,3 \%)$ пациентов, в группе сравнения в $16(17,6 \%)$ случаях. Резистентные к гемостазу формы постпапиллотомических кровотечений в группе исследования выявлены в $1(1,1 \%)$ случае, в группе сравнения в 10 (10,9\%).

Заключение. Двухэтапное выполнение эндоскопической папиллосфинктеротомии с межэтапным эндобилиарным стентированием, у пациентов с планируемым протяженным рассечением большого дуоденального сосочка на фоне его выраженного доброкачественного стеноза или крупных конкрементов магистральных желчных протоков, является эффективным способом снижения частоты возникновения постпапиллотомических кровотечений, преимущественно тяжелых и резистентных к гемостазу форм.

Ключевые слова: эндоскопическая папиллосфинктеротомия, механическая желтуха, постпапиллотомические осложнения, постпапиллотомические кровотечения

Objectives. To decrease the incidence of postpapillotomy bleedings in patients with hemostasis system disturbances occurring in the mechanical jaundice.

Methods. The aim was achieved by the two-staged endoscopic papillosphincterotomy (EPST) with the interstaged biliary ducts stenting. The first stage included slight dissection (up to the separation of the orifices of the common bile and main pancreatic ducts) of the major duodenal papilla and endobiliary stenting. At normalization of biochemical and coagulation parameters, the removal of the endoprosthesis and maximal EPST by cannulation method were performed. Efficacy of the method was assessed by comparing the results in two groups of patients with the mechanical jaundice. In the research group (93 patients) EPST was carried out in two stages. In the group of comparison (91 patients) generally accepted single-staged EPST was applied.

Results. Endoprosthesis displacement in the group of comparison during the first 24 hours was revealed in 5 cases $(5,4 \%)$, in 3 cases $(3,2 \%)$ the bile entered the duodenum freely. In these three patients the stent replacement wasn't carried out as they were functioning. In two cases the endoprosthesis replacement was performed. In the research group the bleeding after EPST developed in $5(5,3 \%)$ patients; in the group of comparison - in 16 (17,6\%) cases. Hemostasis resistant forms of postpapillotomy bleedings in the research group were revealed in $1(1,1 \%)$ case; in the group of comparison - in $10(10,9 \%)$.

Conclusions. Two-staged endoscopic papillosphincterotomy with the inter-staged biliary ducts stenting in patients with the planned extensive dissection of the major duodenal papilla on the background of its marked benign stenosis or large concretions of the main bile ducts is considered to be an effective way to decrease incidence of the postpapillotomy bleedings mainly severe and resistant forms to hemostasis. bleedings

Keywords: endoscopic papillosphincterotomy, mechanical jaundice, postpapillotomy complications, postpapillotomy

Novosti Khirurgii. 2013 Mar-Apr; Vol 21 (2): 89-93

The method of postpapillotomy bleedings prevention

V.V. Yurchenko

\section{Введение}

Развитие эндобилиарной хирургии привело к тому, что постпапиллотомические кровотечения стали достаточно нечастой, однако еще не полностью ликвидированной патологи- ей $[1,2,3]$. По-прежнему встречаются пациенты с нарушениями системы гемостаза на фоне механической желтухи [1, 3, 4], коагулопатией потребления, вследствие присоединения паренхиматозного печеночного компонента [5], делающей постпапиллотомическое кровотече- 
ние чрезвычайно резистентным к гемостатическим мероприятиям. У части этих пациентов (обычно при крупных конкрементах холедоха) необходимо проводить достаточно протяженные (до 2 см) рассечения большого дуоденального сосочка (БДС), что неизбежно повышает риск кровотечения [6], усугубляющего и без того тяжелое состояние пациента.

Безусловно, кроме вышеприведенных факторов, повышающих риск кровотечения, немалое значение имеет характер васкуляризации и диаметр сосудов, находящихся в области линии рассечения БДС, а также технология его рассечения, которое должно проводиться короткими экспозициями электрического тока $[4,6,7]$. Очевидно, что нивелирование некоторых факторов риска позволит снизить как частоту рассматриваемых осложнений, так и их тяжесть, и резистентность к гемостатическим мероприятиям.

Цель исследования: снизить частоту постпапиллотомических кровотечений у пациентов нарушениями в системе гемостаза, возникающими при механической желтухе.

\section{Материал и методы}

С целью снижения риска возникновения постпапиллотомического кровотечения у пациентов со сдвигом системы гемостаза в сторону гипокоагуляции вследствие высокой механической желтухи (общий билирубин выше 150 мкмоль/л), а также коагулопатией потребления на фоне гиперферментемии или иными быстро некорригируемыми нарушениями, ЭПСТ выполняли в два этапа. Первый включал в себя незначительное (до разобщения устьев общего желчного и главного панкреатического протоков в ампуле большого дуоденального сосочка) рассечение БДС (рис. 1). Причем оно могло проводиться как канюляционным способом, так и торцевым папиллотомом, после чего проводилось ретроградное контрастирование желчных протоков. Если при этом желчные протоки заполнялись на всем протяжении, то в их просвет вводился эндопротез (рис. 2).

Эндобилиарное стентирование в подобных ситуациях имеет определенную специфику. Вопервых, независимо от количества конкрементов, их размеров и подвижности проксимальный конец стента должен заходить во внутрипеченочные протоки. Во-вторых, на эндопротез по всей длине должны быть нанесены дополнительные антирефлюксионные зазубрины - это предупреждает дислокацию стента при движении. В-третьих, проксимальный конец стен- та должен быть конусообразно заужен - без этого условия провести его через устье общего желчного протока в ампуле БДС достаточного сложно. После проведения эффективного (оценивалось эндоскопически и рентгенологически по интенсивности выделения желчи, смешанной с контрастом, в двенадцатиперстную кишку) эндопротезирования пациент переводился в хирургическое отделение, где ему проводились консервативные лечебные мероприятия, направленные, в том числе и на нормализацию системы гемостаза. При нормализации биохимических и коагуляционных показателей проводилось удаление эндопротеза и непосредственно за этим максимальная с визуализацией просвета общего желчного протока ЭПСТ канюляционным способом (рис. 3).

Для оценки эффективности двухэтапной технологии ЭПСТ проведен анализ результатов лечения в двух группах. В группе исследования (93 пациента) ЭПСТ выполняли в два этапа по выше описанной методике. В группе сравнения (91 пациент) использовалась общепринятая методика, одномоментная ЭПСТ (с гемостатической целью незначительными по 1-2 секунды экспозициями). Распределение пациентов по полу и возрасту в группах представлено в таблицах 1 и 2.

Как видно из представленных данных, группы исследования и сравнения существенно не различались по полу и возрасту.

Критериями включения в исследование являлись:

1) механическая желтуха с уровнем общего билирубина выше 150 мкмоль/л, или повышение уровня АЛТ, АСТ более чем в три раза, или отклонения в системе гемостаза, выявленные по времени свертывания (по Сухареву), АЧТВ, ПТИ, ПТВ;

2) необходимость протяженного (от 1,5 см) рассечения терминального отдела общего желчного протока, продиктованная или его протяженным доброкачественным стенозом, или крупными (от 0,8 см в диаметре) конкрементами гепатикохоледоха.

Критерием исключения из исследования являлись злокачественные поражения терминального отдела общего желчного протока.

В группе исследования ЭПСТ произведена канюляционным способом у $51(54,8 \%)$ пациента, неканюляционным в $42(45,2 \%)$ случаях. В группе сравнения вмешательство выполнено канюляционным способом в 49 (53,8\%) случаях, неканюляционным у 42 (46,2\%) человека.

Пациенты обеих групп получали одинаковую гемостатическую, спазмолитическую и инфузионную терапию. 


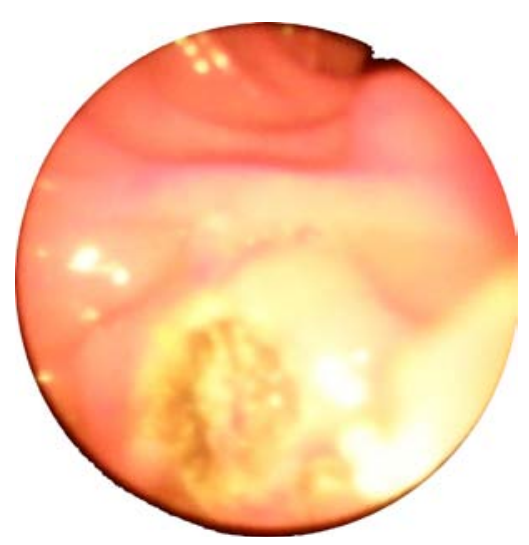

Рис.1. Проведение предрассечения БДС до зоны крупнокалиберных артерий (первый этап ЭПСТ)

Распределение пациентов по уровню желтухи представлено в таблице 3. Очевидно, что пациенты в обеих группах представлены репрезентативно.

Критериями резистентного к гемостазу постпапиллотомического кровотечения считали продолжительность кровотечения более суток при эндоскопическом гемостазе более двух сеансов с использованием диатермокоагуляции или обкалывания в сочетании с орошением раствором феррокрила, а также адекватной инфузионной терапии с обязательным применением ингибиторов протеаз.

Статистический анализ проводили с ис- пользованием непараметрических критериев, различие стандартизованных процентных показателей определяли по критерию углового преобразования Фишера.

\section{Результаты и обсуждение}

В группе исследования через сутки после стентирования у всех пациентов было проведено эндоскопическое исследование с целью выявления возможной миграции эндопротеза и оценки адекватности поступления желчи в двенадцатиперстную кишку. Смещение эндопротеза выявлено в пяти наблюдениях

Таблица 1

Распределение пациентов по полу и возрасту в группе исследования $(\mathrm{n}=93)$

\begin{tabular}{lccccccc}
\hline \multicolumn{1}{c}{ Пол } & \multicolumn{7}{c}{ Возраст (лет) } \\
& $30-39$ & $40-49$ & $50-59$ & $60-69$ & $70-79$ & $79<$ & Итого \\
\hline Муж. & 1 & 2 & 4 & 4 & 5 & 3 & 19 \\
Жен. & 5 & 10 & 12 & 23 & 19 & 5 & 74 \\
Всего & 6 & 12 & 16 & 27 & 24 & 8 & 93 \\
\hline
\end{tabular}

Распределение пациентов по полу и возрасту в группе сравнения (n=91)

\begin{tabular}{lccccccc}
\hline \multicolumn{1}{c}{ Пол } & \multicolumn{7}{c}{ Возраст (лет) } \\
& $30-39$ & $40-49$ & $50-59$ & $60-69$ & $70-79$ & $79<$ & Итого \\
\hline Муж. & - & 2 & 3 & 7 & 3 & 2 & 17 \\
Жен. & 3 & 5 & 17 & 27 & 20 & 2 & 74 \\
Всего & 3 & 7 & 20 & 34 & 23 & 4 & 91 \\
\hline
\end{tabular}

Таблица 3

Распределение пациентов в группах по выраженности механической желтухи

\begin{tabular}{lcccc}
\hline \multicolumn{1}{c}{ Группы } & \multicolumn{3}{c}{ Уровень общего билирубина (мкмоль/л) } \\
& $\begin{array}{c}150-200, \\
\mathrm{n}=22\end{array}$ & $\begin{array}{c}200-300, \\
\mathrm{n}=99\end{array}$ & $\begin{array}{c}300-400, \\
\mathrm{n}=45\end{array}$ & $\begin{array}{c}400-500, \\
\mathrm{n}=16\end{array}$ \\
\hline Группа исследования, $\mathrm{n}=93$ & 12 & 48 & 24 & 7 \\
Группа сравнения, $\mathrm{n}=91$ & 10 & 51 & 21 & 9 \\
\hline
\end{tabular}




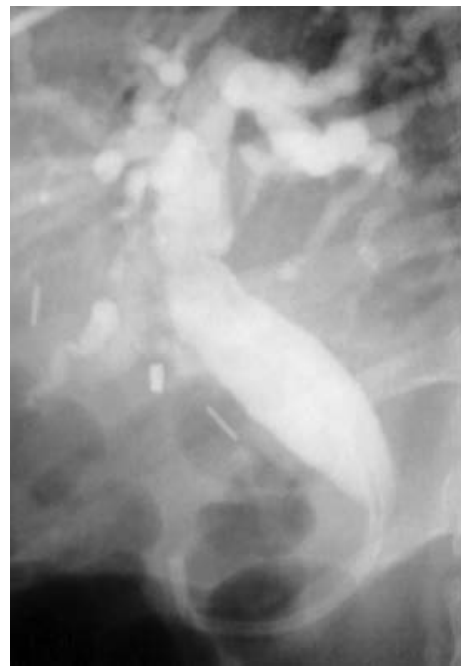

Рис. 4. Частичная (без потери функции) дислокация эндопротеза общего желчного протока

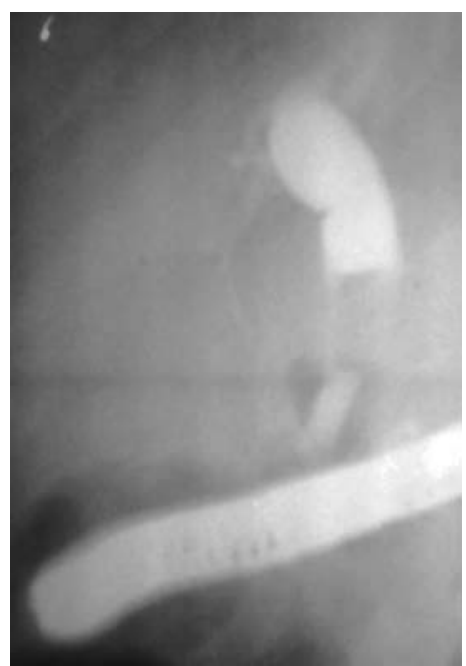

Рис. 5. Крупный неправильной формы конкремент общего желчного протока у пациента с высокой (более 350 мкмоль/л) механической желтухой

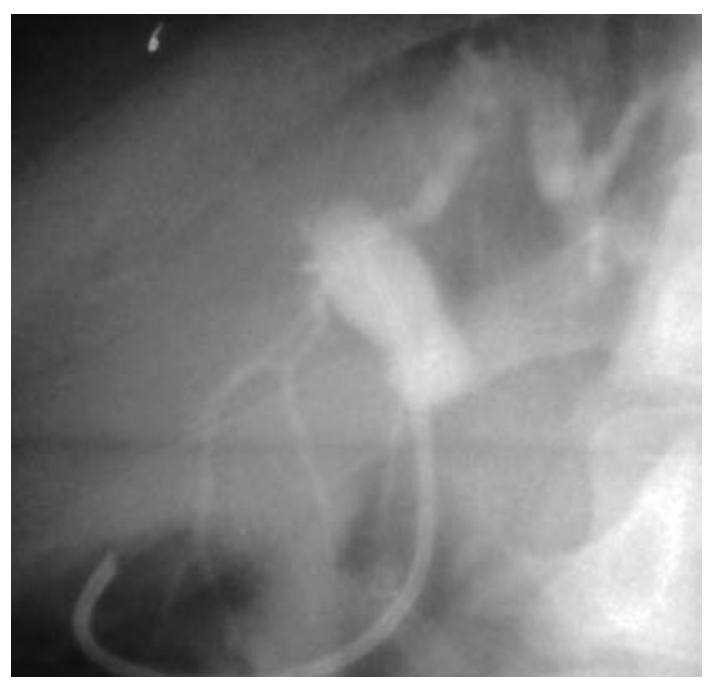

Рис. 6. Заведенный за конкремент и частично дислоцировавшийся эндопротез холедоха
$(5,4 \%)$, при этом в трех случаях $(3,2 \%)$ желчь поступала в двенадцатиперстную кишку свободно. Инструментальная пальпация стента (оценивалась по «подтягиванию» окружающих тканей при захвате эндопротеза петлей) показывала его устойчивое положение, а ретроградное введение контраста демонстрировало положение антирефлюксионной зазубрины в проксимальной части интрапанкреатического отдела общего желчного протока (рис. 4) или выше конкремента общего желчного протока (рис. 5, 6).

В этих трех наблюдениях замену стента не проводили, а повторяли дуоденоскопию через сутки. Во всех трех случаях дальнейшая миграция стента не отмечалась. В одном наблюдении $(1,1 \%)$ было выявлено смещение стента с незначительным поступлением вязкой, темно-коричневой желчи в двенадцатиперстную кишку. Еще в одном наблюдении $(1,1 \%)$, не смотря на свободную эвакуацию желчи, у пациента имела место клиника гнойного холангита - триада Шарко (дополнительно к желтухе появлялась интенсивная боль в правом подреберье и гектическая лихорадка). Двум последним пациентам произведена замена на эндопротезы более широкого диаметра. При дуоденоскопическом контроле через сутки отмечалось адекватное поступление желчи в двенадцатиперстную кишку.

При адекватной эвакуации желчи и стабильном положении эндопротеза в дальнейшем в качестве метода контроля применяли определение уровня билирубина. Снижение уровня общего билирубина находилось в диапазоне $11,7 \pm 5,3$ мкмоль/л $(\mathrm{M} \pm \sigma)$ в сутки. Контроль гемостаза осуществлялся по стандартным показателям: времени свертывания (по Сухареву), АЧТВ, ПТИ, ПТВ. При гипокоагуляции холестатического генеза данные показатели нормализовывались синхронно с купированием механической желтухи, достигая нормы при уровне общего билирубина 71,2 $\pm 8,5$ мкмоль/л $(\mathrm{M} \pm \sigma)$. Гипокоагуляция потребления (на фоне цитолиза гепатоцитов и подъема трансаминаз - 7 наблюдений $(7,5 \%))$ не коррелировала со снижением общего билирубина и требовала более длительного временного интервала между первым и вторым этапами ЭПСТ $-12 \pm 4$ суток $(\mathrm{M} \pm \sigma)$ по сравнению с межэтапным периодом при гипокоагуляции холестатического генеза, составлявшем $5 \pm 3$ суток $(\mathrm{M} \pm \sigma)$. Таким образом, при гипокоагуляции потребления межэтапное стентирование прямым образом не воздействует на причину нарушения в системе гемостаза, а только предоставляет время для его нормализации и проведения максималь- 
Частота развития постпапиллотомических кровотечений

Таблица 4

\begin{tabular}{lccccccccc}
\hline \multicolumn{1}{c}{ Группы пациентов } & \multicolumn{2}{c}{ Общее } & \multicolumn{3}{c}{ Тяжесть постпапиллотомического кровотечения } \\
& \multicolumn{2}{c}{ кол-во } & \multicolumn{2}{c}{ легкое } & \multicolumn{2}{c}{ средней тяжести } & \multicolumn{2}{c}{ тяжелое } \\
& абс. & $\%$ & абс. & $\%$ & абс. & $\%$ & абс. & $\%$ \\
\hline Группа исследования, $\mathrm{n}=93$ & 5 & 5,3 & 4 & 4,3 & 1 & 1,1 & - \\
Группа сравнения, $\mathrm{n}=91$ & 16 & 17,6 & 3 & 3,4 & 7 & 7,7 & 6 & 6,6 \\
\hline
\end{tabular}

Примечание. Достоверность различий между группами статистически значима ( $\mathrm{p}=0,00001)$.

Таблица 5

Частота развития резистентных к гемостазу форм постпапиллотомических кровотечений

\begin{tabular}{lcc}
\multicolumn{1}{c}{ Группы пациентов } & Частота развития резистентных к гемостазу форм & $\%$ \\
& абс. & 1,1 \\
\hline Группа исследования, $\mathrm{n}=93$ & 1 & 10,9 \\
Группа сравнения, $\mathrm{n}=91$ & 10 & $\%$ \\
\hline
\end{tabular}

Примечание. Достоверность различий между группами статистически значима ( $\mathrm{p}=0,00001)$.

но гемостатичного рассечения БДС в области крупнокалиберных сосудов.

Частота развития постпапиллотомических кровотечений в исследуемых группах представлена в таблицах 4, 5.

Как видно из представленных данных, двухэтапная ЭПСТ с профилактическим стентированием желчных протоков у пациентов с риском развития постпапиллотомического кровотечения снижает вероятность его возникновения с 17,6\% до 5,3\%. Особенно важно, что уменьшается частота кровотечений резистентных гемостазу форм.

Эффективность двухэтапного метода обусловлена, на наш взгляд, следующим. Рассечение большого дуоденального сосочка в области наиболее крупных сосудов происходит во время второго этапа, когда нарушения в системе гемостаза, возникающие на фоне механической желтухи, купированы за счет восстановления желчеоттока по эндобилиарному стенту, установленному на первом этапе ЭПСТ после выполнения незначительного до разобщения устьев общего желчного и главного панкреатического протоков - рассечения фатерова сосочка.

\section{Заключение}

Двухэтапное выполнение эндоскопической папиллосфинктеротомии с межэтапным эндобилиарным стентированием у пациентов с планируемым протяженным рассечением большого дуоденального сосочка на фоне его выраженного доброкачественного стеноза или крупных конкрементов магистральных желчных протоков является эффективным способом снижения частоты возникновения постпапиллотомических кровотечений, преимущественно тяжелых и резистентных к гемостазу форм.

\section{ЛИТЕРАТУРА}

1. Эндоскопическая ретроградная панкреатохолангиография и эндоскопическая папиллосфинктертомия у больных механической желтухой / А.И. Брегель [и др.] // Сибир. мед. журн. - 2009. - № 6 - С. 53-55.

2. Султанов С. А. Модифицированная двухэтапная тактика лечения желчнокаменной болезни, осложненной холедохолитиазом / С. А. Султанов, А.А. Архипов // Эндоскоп. хирургия. - 2004. - № 4. - С. 26-29.

3. Complications of ERCP / J. S. Mallery [et al.] // Gastrointest Endosc. - 2003 May. - Vol. 57, N 6. - P. 633-38.

4. Eimiller A. Complication of endoscopy / A. Eimiller // Endoscopy. - 1992 Jan-Feb. - Vol. 24, N 1-2. - P. 176-84.

5. Подымова С. Д. Болезни печени : рук. для врачей / С. Д. Подымова. - М. : Медицина, 1998. - 704 с. 6. Complications of diagnostic and therapeutic ERCP: a prospective multicenter study / E. Masci [et al.] // Am J Gastroenterol. - 2001 Feb. - Vol. 96, N 2. - P. 417-23.

7. Biliary stent endoprosthesis: analysis of complications in 113 patients / P. R. Mueller [et al.] // Radiology. - 1985 Sep. - Vol. 156, N 3. - P. 637-39.

\section{Адрес для корреспонденции}

655017, Российская Федерация,

Республика Хакасия, г. Абакан, ул. Ленина, д. 92, ФГБОУ ВПО «Хакасский государственный университет им. Н. Ф. Катанова», кафедра хирургии,

тел.: 8902 990-59-22,

e-mail: yurchenkovld@mail.ru,

Юрченко Владимир Владимирович

\section{Сведения об авторах}

Юрченко В.В., д.м.н., профессор кафедры хирургии ФГБОУ ВПО «Хакасский государственный университет им. Н. Ф. Катанова».

Поступила 30.09.2012 г. 